\title{
More international grads seek residency
}

$\mathrm{T}$ The number of Canadian graduates of foreign medical schools who apply for residency spots back home is growing and a smaller percentage are actually getting matched.

Between 2008 and 2013, the number of Canadians studying abroad (CSA) who applied for Canadian residency positions increased by $292 \%$ (181 in 2008 to 709 in 2013), according to data from the Canadian Resident Matching Service (CaRMS). And although the number of CSA's who were matched to a residency position increased from 95 to 258 , as a percentage of applicants, the matches decreased to $36.4 \%$ from $52.5 \%$ during the same period (see Table 1).

There are a set number of positions for international medical graduate (IMG) candidates, regardless of whether they are Canadian-born or not. Candidates who graduate from Canadian universities are first in line for residency spots. This doesn't sit well with some CSAs who say they should be given the same preferential treatment as their Canadian colleagues who study domestically.

The Society of Canadians Studying Medicine Abroad, an advocacy group for CSA based in British Columbia, argues that your country of training should play no role in the selection process. "We hope to help change the system so that all Canadians have equal opportunity to probably the most prestigious calling in Canada based on their merit, not where they went to school," says Rosemary Pawliuk, president of the group and a parent of a medical student studying abroad.

Omar Abdulrahman, a Canadian studying medicine at the Pomeranian Medical University in Szczecin, Poland, agrees with the society's aims and says that the current preferential treatment of Canadian-trained candidates is an infringement of his charter of rights. "The basic principle of equality is the right to compete against all other Canadians for opportunities on the basis of individual merit without discrimination."

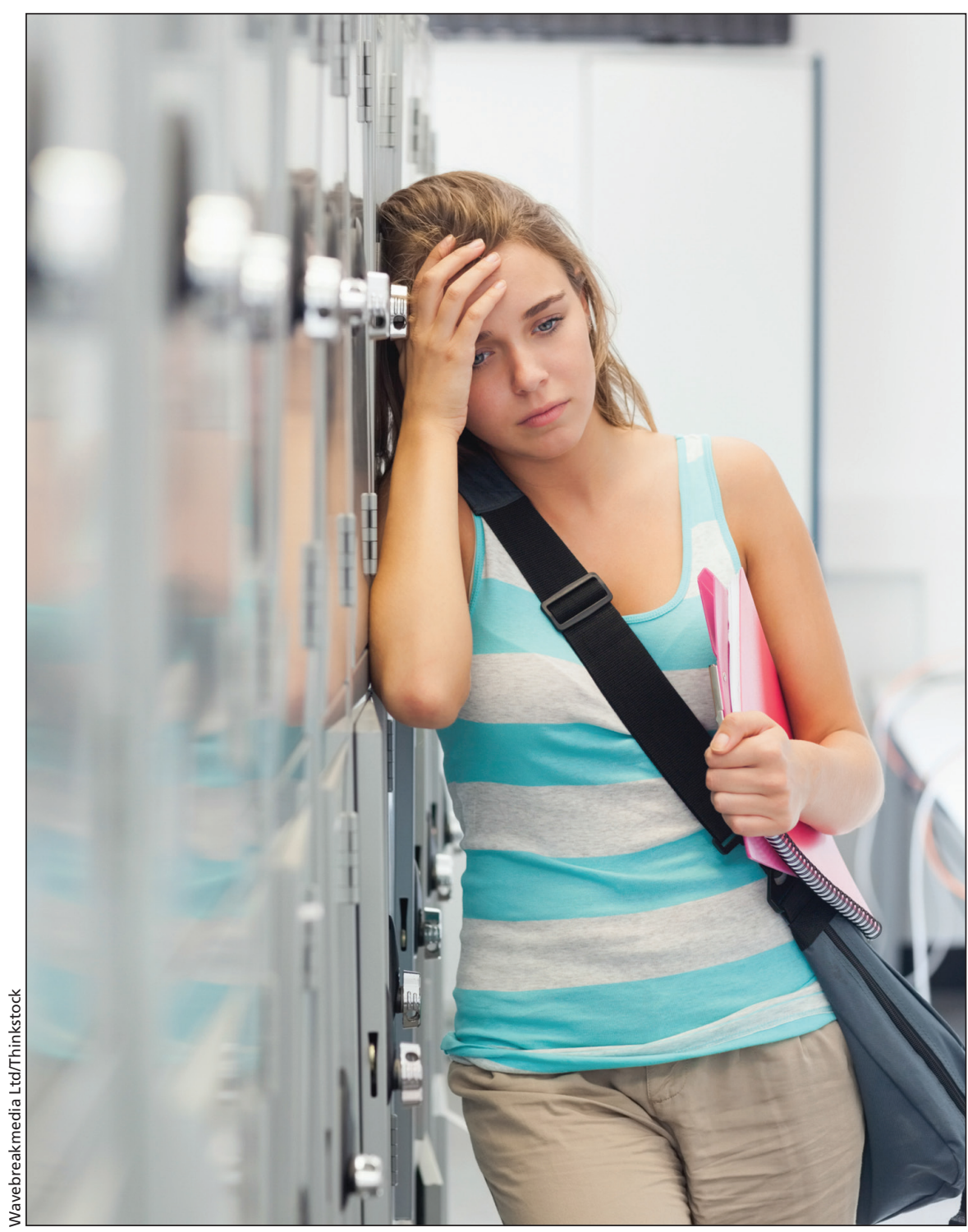

In 2013, only about one-third of Canadian graduates from foreign medical schools were matched to residency slots, down from more than a half in 2008.

"We believe it's unfair because we were born or raised in Canada, and should be equal to Canadian medical graduates," added Abdulrahman, who is president of the 171-member Canadian Medical Students in Poland Association.

The idea that Canadian citizens who study abroad should be considered equal to Canadians studying domestically is familiar to Sandra Banner, executive director and CEO of CaRMS. In response, Banner says "An IMG is not a definition of citizenship, it is entirely and only an educational definition. And under the educational definition, the CSA fits perfectly."

The health care system sets a quota for IMGs, regardless of country of origin, in order to maintain a high output of domestically trained physicians. Many of the 3600 Canadians currently studying medicine abroad harbour misconceptions about the process and prospects for getting a Canadian residency 
spot according to a recent $C M A J$ Salon article.

Ian Brasg, vice-president education for the Canadian Federation of Medical Students, also points out that Canadian medical graduates are more likely to practise in rural settings and represent a broader social economical spread than CSAs. "Given that Canadian medical school entry positions are numerically designed to meet the needs of the Canadian population while taking into account a roughly $20 \%$ contribution from immigrating physicians...we don't see a need ... for CSA to meet our capacity needs."

Brasg is also concerned about the quality of education abroad. Canadian schools are accredited by the Liaison Committee on Medical Education and the

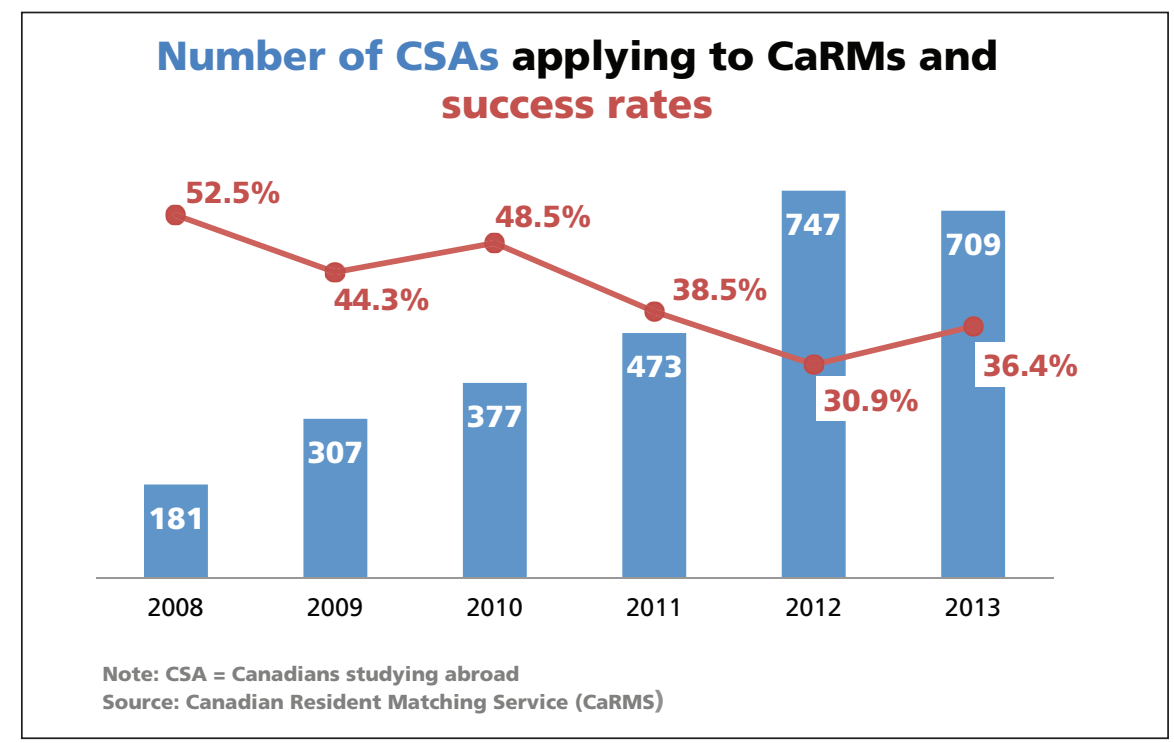

Committee on Accreditation of Canadian Medical Schools. "Our foreign colleagues are trained in an environment of varying quality," says Brasg. Some receive strong clinical training, but others receive little more than observerships, he added.

A CaRMS survey of 1082 CSAs (a response rate of $30.3 \%$ ) estimated that more than $90 \%$ hoped to return to Canada. CaRMS is currently conducting a similar survey to update those numbers. The survey featured in a 2010 report, which also calculated the median debt of CSAs to be $\$ 160000$, compared with $\$ 71000$ for Canadians studying domestically during a similar time period.

CaRMS does not publish a breakdown of how many IMG candidates are CSAs; this information is only available for specific years through external reports such as this current article. The fact that these statistics are not commonly available, may partly explain why Canadians wishing to practise medicine in Canada continue to study abroad. Wilson Kwong, Kingston, Ont.

CMAJ 2014. DOI:10.1503/cmaj.109-4788 